\title{
SIMULTANEOUS CLASSES, A PEDAGOGICAL ALTERNATIVE
}

\author{
Carmen Maria CHISIU, Ph.D., \\ „L. Blaga” University from Sibiu \\ carmenmariachisiu@yahoo.com
}

\begin{abstract}
In the Romanian educational system still exists simultaneous classes in which, on the grounds of a small number of pupils on a level of study, in the same classroom under the guidance of one teacher, operates more classes. If the teacher can make teaching an art, this way of organizing learning can be an opportunity for students. In this paper we suggest a few ideas that may enhance the effectiveness of school learning, under simultaneous classes.
\end{abstract}

Keywords: simultaneous classes, collaborative learning, interactivity, communication, problem solving

\section{Introduction}

The idea of this work was born out of the need to share, on the one hand, the personal experience gained as a teacher in a Step by Step class, as a student in a simultaneous classroom, with students of grades I to IV, under the guidance of the same teacher, a class where there weren't any non-promoted pupils, the experience as a school inspector for primary education and the experience of a pedagogy teacher with a cosntructive orientation in terms of school education.

Simultaneous education is an alternative to creating learning opportunities in school environment with small a number of pupils. The creation of simultaneous teaching classes is a solution, a pedagogical alternative, in response to problems recorded in recent years, from the perspective of pupils, in decreasing order, through a constructivist approach to school learning.

According to the annex to the MECTS Order no. 3062 / 19.01.2012 on the approval of the methodology for the organization of the pre-university education classes in simultaneous education, the simultaneous teaching is specific to the areas where the number of pupils is very small. Because of this, students learn in classes of two, three or even four age groups. We can 
consider the Montessori pedagogy, in which in the same class learn children between 6-9 years and 9-12 years and the Step by Step classes, in which, at the same time, in the classroom, the activities are totally different, as pedagogical realities which sustain efficiency and encourage learning at the same time.

In order to offer children who attend simultaneous education, according to the Convention on the Rights of the Child, art. 29 equal opportunities for development with the others, as things are now in Romania, we should intervene with changes, so that the didactic approach is organized according to their needs and interests, which means good knowledge of children, a careful surveillance of each person's progress, combining optimally the types of teaching strategies, constantly harmonizing the didactic strategies used, to the reality of the classroom, and the time spent at school to be used extremely efficiently.

\section{A short research}

We started from the hypothesis that teachers do not feel ready to work in simultaneous classes.

Through google drive, we submitted a questionnaire, completed by 38 teachers teaching in simultaneous classes, a questionnaire consisting of 10 questions. We also used direct observation as a research method.

The results are as follows:

Most of the teachers, $80 \%$, think that they use much and very much individual work in their school activity;

Most of the respondents estimate that they use little and very little group work of 3,4 or 5 pupils;

$80 \%$ of the questioned teachers appreciate that they use little and very little activity in pairs;

$80 \%$ think they are using a lot of frontal activity;

$70 \%$ appreciate that they feel a little and very little prepared to work in simultaneous classes using differentiated learning;

$60 \%$ are ready to work in simultaneous classes using cooperative learning; $60 \%$ are ready to work in simultaneous classes using student self-evaluation; $70 \%$ feel ready to use tutors from students;

$80 \%$ of teachers appreciate that they feel very little and little prepared to organize student-centered school activity.

Observing the assistance for obtaining the didactic degrees, evaluating activities as an ARACIP evaluator, the pedagogic practice, gave me the opportunity to appreciate that in most of the situations where the class activity is organized in small groups or in pairs, each student works his own 
worksheet, his own product or exercise, even if they are grouped. Very rarely, genuine cooperation activities are organized.

Both individual and group and frontal work, student tutoring, learning differentiation, self-evaluation are teaching practices that, at the same time, have a peculiarity in education that would be appropriate to practice in guided training.

$100 \%$ of teachers consider necessary a professional development course on the subject of simultaneous education.

In addition to individual study, methodical activities prepared in the spirit of student-centered education, the teachers from the simultaneous classes need training courses on the specific subject in which to practice to form psychopedagogical skills specific to the simultaneous activity.

Following the results of the short research, we will try to bring argued examples, which the teacher can use in didactic activity, by mastering independent work with the frontal and group work (through collaboration and cooperation), turning to account the potential of the students, turning to account the differences of age, using didactic means, appropriately and carefully selecting the exercises and the contents used. This is the decisive factor in achieving performance in such classes.

\section{Frontal activity in simultaneous education}

The activity in which the main actors' action areas are clearly delimited: the teacher and the pupils, is called frontal (Hubbard et all, 1984). The teacher is at the heart of the activity and has full control over any interaction: teacherstudent; student-student, student-teacher.

The teacher is the only person with the power to decide what is happening in the classroom. The role of the pupils is to listen to and perform the tasks required by the teacher. In the same frontal activity, which is indispensable to school learning, in a student-centered approach, the teacher is no longer the only person in the classroom but is the one who turns to account the experience and the potential of students, them becoming the resource and the builders of their own knowledge.

A group of students, or a representative of them, can address the classroom when presenting the results of the group activity. Depending on the didactic task they had to fulfill, the group can ask questions for the class, can demonstrate or answer their colleagues'questions.

The frontline organization of the simultaneous class is also the situation where all students in one year of study work with the teacher: they participate in the explanation that the teacher offers for understanding new knowledge or for accomplishing the task or students of all the years, attends the morning meeting, watch a movie, a play, they sing, they play a role, etc. 
In order to focus their attention on the important aspects of learning, it is always good to remember that at the beginning of watching a movie or listening to a story, students are clearly communicated the task, for example:

Task 1. Watch the movie so you can name the characters who participated in the action. Task 2 . Identify a quality for each character.

Tasks may be different, for different classes. More effective would be the stating and the explanation of the tasks, they should also be written so that students can return to them during the course of their work and at the time of evaluation.

The morning meeting can become a daily practice, as in the Step by Step alternative, on a topic chosen by the teacher or proposed by students. Stating a problem from the thematic unit that they study, during the morning meeting we focus on developing oral communication. In the first part of the class, the content may be the same for all pupils, but the tasks and products to be done are differentiated according to age and individual peculiarities. We suggest that students should be the ones who choose which tasks they want to accomplish. We may have the surprise that the younger ones may want to achieve performance-enhancing tasks designed for higher grades. In this way, we are in line with one of the principles of human psychology children must be allowed to take as many decisions as possible.

In the morning meeting, communication exercises are made, depending on the topic chosen, through an integrated approach. They can talk about a community event, about a historical event that happened on that day, about a story lived by a character from literature, history, a literary work, about a meteorological phenomenon, about significant experiences / events that have happened at the end of the week, they can read fragments of the texts studied in the ongoing topic unit, articles in newspapers, magazines, they can talk about what may be more important and current in the life of the community. Pupils ask questions from each other by the message, organize didactic games aimed at the development of the vocabulary and it is encouraged the participation of all.

This is a way to allow children to use the experiences they acquire within school, and on the other hand they can apply what they learn at school in their daily lives so that school becomes the place where learning takes place for life, a principle characteristic to the Montessori, Freinet, Waldorf and Step by Step alternatives.

Given that the number of students is not too high in relation to the size of the classroom and the furniture is not fixed, spaces can be organized in which the two or three groups of pupils in different classes can perform front-end activities without disturbing their own spaces to each group. In such a classroom, frontal activity will be deployed in the space where chairs or 
benches are arranged in the form of a horseshoe. This arrangement is best, because visibility is better, the teacher can see all students, who in turn see most of their colleagues without the need to return. All frontal, but interactive, for a thematic unit, for example: Let's get together with colleagues, work can start with exercise Find quality, walk through the classroom, wearing a ticket on the back, each participant writes to colleagues who He knows a good enough quality on the ticket he wears on his back. Those small who can not write yet, draw a symbol or appeal to the greatest. At the end of the activity, each reads the qualities he / she has written on the ticket and makes an analysis: identifies those he / she would have attributed. The following day you can write recommendations for changing behavior to better relate to others. This activity was regarded not only as an exercise of communication, but also as knowledge and self-knowledge. The simultaneous class offers even an advantage: the age difference and training among students make the interaction more closely related to the actual situation faced by students beyond the walls of the school. In these games he participates directly, carrying his own ticket and making notes on students' and teacher's tickets. His involvement aligns with the primacy we learn together, we learn from each other, we are a community specific to the Step by Step alternative.

Other examples of frontal activities that are also suitable for simultaneous classes are: teaching new knowledge, checking understanding of new knowledge, consolidating exercises, reading out loud, solving some blackboard exercises, classroom training and reading and discussing newspaper extracts, magazines, books, commenting on local or national events of students' interest, didactic games, to which all students participate. The activities to which all students participate are very important in simultaneous teaching as they contribute to the welding of the group of students, which will make them communicate freely, without fear of being "denounced" to parents or other children in town. Frontal work is characterized by a rigorous control of the teacher who determines the content, interaction, rhythm, duration of activity. The teacher also corrects students' mistakes and assesses the level of achievement of the didactic task. I have already mentioned that especially in the context of simultaneous education, the teacher is not the only person who can interact with the class. However, this type of organization of the class has advantages and disadvantages that require alternation with individual and group activities.

\section{Independent activity in simultaneous education}

By independent activity we understand the way of organizing the training educational activity, which consists in the activity of enriching knowledge 
and skills, without the help of others, according to the instructions given by the teacher.

The content of the independent activity must have a clearly specified purpose, dimensioned in such a way as to occupy all the time affected by this activity with well understood tasks. Here, differentiated and individualized treatment will be used. Copying or transcribing texts is recommended only in the $1^{\text {st }}$ grade, with the aim of practicing the calligraphic writing of letters. The tasks in working independently should require the pupil in the vicinity of the development, according to Vagotsky's theory; complex enough to be stimulating, but at the child's level of understanding and processing, in order to be able to be stimulated and motivated. The content of self-employed exercises must be attractive to capture the students' attention, to stimulate their creativity, thus enabling them to solve the tasks they receive without distracting their attention to other activities in the classroom.

Depending on the specifics of the didactic task, the teacher must assign tasks so that students can not copy from one another, even if they do the same type exercise. For example, if the students have to summarize a text, the task is identical, but the texts must be different. It is recommended that students be given the opportunity to ask for support from their colleagues for understanding, but the work itself should be done by themselves. This is also a practice that has been verified in the Step by Step class and from which everyone has to learn: the one who explains consolidates his knowledge, and the other can explain his confusing things.

Examples of activities pertaining to individual work: reading a text and filling in a reading sheet prepared in advance by the teacher, searching for information or words in dictionaries, encyclopedias, extracting the main ideas, summarizing or commenting on a text, writing letters, texts, telegrams, announcements, various mathematical calculations, to find out the size of a surface, drawings, objects, games, teaching materials etc.

\section{Activity in groups, in the context of simultaneous education}

Group work involves working with someone, active participation in the pursuit of a common goal in learning.

Collaborative learning involves offering mutual support in accomplishing tasks, by ensuring understanding through dialogue, through exchange of ideas, through mutual learning.

Cooperative activity requires different tasks to be accomplished, but by assembling they lead to getting a common product.

Both cooperative learning and collaborative learning imply taking responsibility for both learning and others. 
The group of pupils in the case of simultaneous teaching is composed of two, three or even four age groups and training levels. There is no point in dividing these groups into subgroups unless there are more than five children in a class.

The advantages of working in a group are multiple: time is gained by multiplying work points, increasing the active participation of each student; students learn from each other, the source of knowledge is not only the teacher; social facilitation is achieved by stimulating the individual due to the presence of others; the group achieves the collection of resources; they also cumulate skills, contributions, information; more minds do better than one; it reduces the number of errors, it increases the accuracy of the solution; "blind spots" are corrected; it is easier to see the mistakes of others than personal ones; the group develops the ability to think critically, and last but not least, children learn to work together, which is a great gain for their training for life.

Group work is an absolutely necessary way in simultaneous classes where pupils are required to learn to solve the problems they have raised, alone or with the help of their colleagues. The disadvantage of group work in simultaneous education is the inevitable noise when more students speak at the same time. In a simultaneous class this may be an impediment to the other group's activity. It is also possible to have indiscipline problems. It is necessary to draw up a worksheet for each group explaining the steps, the stages needed to solve the tasks and the place where support materials can be found; we can compare it with the programmed learning as a method of education.

Through the cooperation work, posters can be made in which the contents of a lesson, the relationships between different concepts are drawn through drawings, tables or schemes. Through collaborative work, joint products can be made by contributing to the fabrication of a component of the fruit basket or a step in the making a product: one can shape, another cuts, one sticks into a common product - Spring garden.

Working in pairs, which is also a group work, is the easiest way to be organized, even in classrooms with fixed furniture, because students are usually two in desks. Another advantage of working in pairs is the active participation rate of students. Virtually half of the students are permanently active. Advantages of working in pairs, applicable in simultaneous education: increases the percentage of active participation of students, encourages students' collaboration, the two can correct each other, without fear of being ridiculed, can explain the less clear aspects of the didactic task, it can be organized at any stage of the lesson to achieve different goals: oral or written exercises, understanding of written messages, exercises and 
problem solving, self-correction assessment of individual work, each correcting with the help of Colleague who oversees and helps him.

\section{Ways of combining frontal, individual and group activity}

When we do the teaching of new knowledge and we want the formation of some skills, for example - performing the multiplication of two numbers, it is important to follow some stages. First, the teacher demonstrates and at the same time explains an exercise. The second stage, one of the high-potential students, does blackboard exercise, explaining out loud what he is doing under the teacher's supervision. Stage three, in pairs, the students solve each other's supervision, one exercise. The next step, each student solves two multiples alone and in the last step, on the board, under the supervision of the teacher, the students with low potential solve another exercise. This approach is recommended to be used whenever the purpose is to train working skills, where, starting from the maximum help received from the teacher and then from colleagues, the pupils are getting more and more out of support and get to solve by themselves, in a controlled form, in order to avoid errors.

We engage in group activity almost involuntarily with the concept of interactive learning.

Activity under simultaneous conditions does not constitute an impediment to using interactive methods.

Snowball, is one of the interactive methods that can be used successfully in the simultaneous class, combining the individual activity with the group activity.

The method involves reducing the number of elements, aspects, facets of a problem / situation and focusing on the essentials. It can be used in preparation for starting a thematic unit, if it is not entirely new, or for argumentation or fixation, at the end of the thematic unit. The method can be used at the end of The Field Thematic Unit, for the topic - Advantages of the inhabitants in the field areas.

Steps needed to complete the method:

- Divide the class into groups of 4-5 students!

- Tell the topic!

- Each member writes his / her ideas in response to the given topic and puts the card in the center of the table.

- Each member reads all the ideas and hierarchies them through individual activity.

- Students are discussing at the group level and will retain the first 2-3 more relevant ideas 
Another method that can be used is the Double Entry Journal. It is a method by which readers establish a close connection between text, film, painting, drawing, musical piece and their own curiosity and experience. The method can be used at the beginning of the Water theme unit - The water, starting from tokens that represent different forms of water existence in nature.

Steps needed to complete the method:

- Each divides a page into two columns, pulling a vertical line in the middle.

- On the left side they will note passages, elements that particularly impressed them, which surprised them. On the right they will comment on that passage.

- Why did they note it?

- What made them think of?

- Why did it intrigue them?

- They read at the level of the group what they wrote.

- The teacher makes his own comments.

A method through which the student with the support of his colleague and under the guidance of the teacher learns how to learn is I Know / I want to know / I have learned.

In small groups, preferably in pairs, students remember what they already know about a particular topic and then ask questions.

Steps required to complete the method:

1. Students build a table of the kind

\begin{tabular}{|l|l|l|}
\hline I Know & I want to know. & I have learned. \\
\hline & & \\
\hline
\end{tabular}

2. For 5 minutes, teacher asks students to form pairs and write in the first column everything they know about the topic that is going to be discussed.

3. Within the group, by mutual reading, each reads the others in each column.

4. Teacher asks students to read the lesson in the textbook or a training sheet prepared by him, and fill in the I have learned section with the answers to the questions asked and other interesting and important ideas found in the record or lesson.

5. Through a frontal activity within the group, questions are left unanswered, they are discussed, solutions are found, and sources are provided where they can look for this information. Every child completes the heading I have learned, with the missing ideas.

Beware!

It is a method that is suitable only for lessons that really stir curiosity in the mind of the child. 
With the same success, the ICSRTE method - The Interactive Classification System for Reading and Thinking Efficiency can be used

- It is a way of encoding the text that allows the learner to read and understand, to actively and pragmatically read some content.

- It is a method that can be used to teach students how to learn.

- It is a method with a strong formative character.

Steps required to complete the method:

During the reading, students mark in the text using the following notations:

The knowledge confirmed by the text $\sqrt{ }$

New knowledge not yet encountered +

Uncertain, confused knowledge that deserves to be investigated ?

The knowledge that was denied / contradicted by the text -

The information obtained individually is discussed in the group;

After the discussion, the information is entered individually in a table:

\begin{tabular}{|l|l|l|l|}
\hline$\sqrt{ }$ & + & $\boldsymbol{P}$ & - \\
\hline & & & \\
\hline
\end{tabular}

Careful!

- The columns '?' And '-' are the teacher's center of interest. The information in these headings needs to be clarified, firstly, through a pair / group discussion. If they can not be clarified, at the pair / group level, they are discussed with the whole class and with the teacher's support.

- Problems that can not be elucidated on the spot can be set as homework, the teacher indicating the source from which students can get information. Thus, they will be material for the next lesson.

For the development of creativity, the Free Texting method, which is specific to the Freinet alternative, can be used successfully.

- It is a method that increases student's interest in written composition.

Stages:

1. Students are divided into groups of 4.

2. Each student writes the headings of three texts on a file, which would like to write them on half a page.

3 . Everyone communicates titles to colleagues in the group.

4. They choose the text that they would like to listen to.

5. Each student develops a draft, a plan of ideas, key words, feelings, thoughts, without a logical, chronological order. The correct writing problems can be ignored. 
6. Each student then draws up a draft with reorganizations, in which one line is written, in order to make corrections, additions, individually or in consultation with a colleague or teacher.

7. Rewrite and correct the text, each with a colleague.

8. Read each text within the group.

9. At home the text is prepared for presentation: calligraphic rewriting, filling in with drawings, computer writing, page layout is also an element of creativity the student should be aware of.

10. It is possible to create a book of the class, with texts made on various occasions.

Beware!

It takes an hour for such an activity.

It is recommended to allow the necessary time.

The teacher has to teach his students how to present their creation: voice tone, nonverbal language, visual contact.

Under the conditions of simultaneous education, there is always the problem of time, the time gap between the required time and the estimated activities simultaneously proposed. The surplus of time is also used in favor of the student who can: check the humidity of plants in the Green Corner, fill in the Journal of the class, look for information about the author of the text they are going to study at Romanian language, in the Class Library books or on the Internet, to create figurines with TANGRAM squares or the ORIGAMI technique, to help students of the lower class to complete the collective work, to prepare the materials for the next hour of practical skills, to respond in writing to the partners of the European School project, to sort out or pack the donated toys for Placement Center children, to uncover the logic and perspicacity of the existing library or in the basket with extra problems, to consult the reading list with colleagues, to name as many objects where the picture can be found. These tasks can be put down somewhere and students can choose to do what they want.

In order to integrate and interdisciplinary approach to school learning, subjects for Art and practical abilities will be directly related to the literary texts studied: - Autumn Carpet, made by varied techniques, according to the curriculum.

Works can be obtained by group work and can be used as interior design elements in the classroom.

Under the conditions of simultaneous education, there is always the problem of time, the time gap between the required time and the estimated activities simultaneously proposed. The surplus of time is also used in favor of the 
student who can: check the humidity of plants in the Green Corner, fill in the Journal of the class, look for information about the author of the text they are going to study at Romanian language, Class Library books or the Internet, To create figurines with TANGRAM squares or the ORIGAMI technique, to help students of the lower class to complete the collective work, to prepare the materials for the next hour of practical skills, to respond in writing to the partners of the European School project, to sort out Or pack the donated toys for Placement Center children, to uncover the logic and perspicacity of the existing library or add-on collection, to consult the reading list with colleagues, to name as many objects as possible Finds the image. These tasks can be noted somewhere and students can choose to do what they want.

In order to integrate and interdisciplinary approach to school learning, subjects for plastic education and practical abilities will be directly related to the literary texts studied: - Autumn Carpet, made by varied techniques, depending on the program.

Works can be obtained by group work and can be used as interior design elements in the classroom.

\section{Conclusions}

The complexity of didactic activity in simultaneous classes brings many difficulties, which can contribute to poor performance, to school failure of students if these difficulties are not overcome. One drawback is the fact that in these classes, many times, do not arrive teachers capable of making education an art, a condition in which simultaneouseducation could be a success story. The fact that the teacher guides the activity of several classes, being only partially involved in the life of each age group, puts the students in the situation to build their personal knowledge, individual activity and intercourse with their colleagues and at the same time exercise extremely useful socio-emotional skills. Also in the real way, it is created the opportunity, born of obligativity, that students acquire much more independence in the organization and monitoring of school activity, making it a valuable attitude to life, which is lacking in the mass education; pupils in primary education often become overly addicted to the teacher.

Under the conditions of the simultaneous class, the focus is mainly on how and what is happening in the classroom. The teacher's dismay, his major concern is the learning process, the involvement of both the students and the teacher. These observations do not necessarily describe a method, especially an educational philosophy characterized by an interactive, communicative approach of cooperation between pupils as well as between pupils and teachers. The teacher is part of the process, not only conductor and external 
observer. In simultaneous education in particular, the essence is the use of what they already know and can do by supporting one another, sharing each other's experiences, knowledge, way of working to learn something new. Children easily learn from each other all kinds of things, they can learn useful things as they learn how to use the merry pranks, how to use the sling, how to make paper ships, and intellectual work skills.

We only need to create favorable conditions, a well-prepared environment, but leaving a degree of freedom.

In order to have teachers ready to successfully achieve simultaneous classroom learning, besides individual study and training through methodological activities, it is absolutely necessary to train them through a systematic program.

\section{References}

Burke Walsh, K. (1998). Creating classes targeted needs children 8-9-10 years CEDP Step by Step. Bucharest.

Cerghit, I. (2003). Alternative and complementary Training Systems. Aramis Publishing House. Bucharest.

Cucoş, C., (2001., History of ideas and doctrines teaching pedagogy fundamental. Polirom. Iasi.

Steiner, R. (2001). Art Education. Methodology and Teaching (second edition). Ed. Triads. Cluj Napoca. 